\title{
Psychiatry and religion: a general psychiatrist's perspective
}

\author{
John L. Cox
}

\begin{abstract}
This paper contributes to a debate about the nature of religious belief and its relevance for the practice of psychiatry. The need for dialogue is recognised not only because of multi-falth UK society but also because mental health services are now more tailored to the expectation of patients. To understand the posslble relevance of spirtual and existential dimensions to mental illiness, even in a secular society, has become more necessary. Training, service dellvery and research issues are brielly addressed.
\end{abstract}

To understand the nature of the relationship between psychiatry and religion is a complex task because of difficulty defining these subjects and the need to recognise the limitations of an author's particular perspective. And for some psychiatrists any attempt to explore the nature of this relationship is regarded as an irrelevant luxury and religious belief may be ignored or even pathologised. These considerations may partly explain why most psychiatrists do not readily discuss their own religious belief even when it is a profound expression of their personality or cultural background and may influence their approach to medical ethics and determine their weltanshaung.

A Western psychiatrist attending a conference in India or Pakistan may be surprised when religious practice (including prayer, song and exhortation) is included in a scientific programme. Such an experience is an acute reminder of the extent of secularisation within Western society in which religious practices are now less commonly encountered in hospitals or professional meetings, and the announcement of Sunday worship schedules, arrangements for an emergency Baptism and the hospital carol service may remain as the only reminder of the Christian philanthropy which previously directly influenced hospital care. Nevertheless, in North America (Lukoff et al, 1992) a survey found that

Based on a paper read at the Annual Meeting of the Royal College of Psychiatrists. Scarborough. July 1993. and a chapter to be included in a book about religion and mental health edited by Dinesh Bhugra, to be published by Routledge in 1995. over $80 \%$ of the population believed in a God or spiritual force although they did not necessarily practise any specific religion. But mental health professionals were less likely than their patients to practise religion or hold a religious belief. This distance between the religious belief of a health professional and patient is referred to as the 'religiosity gap' and is evidence of an 'unmet need' for patients as the relevance of their own spirituality to the understanding of their 'illness' may not be recognised by an unsympathetic health worker. Mental health services for a multicultural society, however, are now required by government to take into account the values and beliefs of black and other ethnic minorities as well as the religious beliefs of the majority community: a requirement which places the teaching of transcultural psychiatry and aspects of comparative religion as a core content for the training of psychiatrists, and other mental health professionals.

This need to consider spiritual values and ethical mores as well as religious practice to provide a comprehensive mental health service is somewhat novel, yet increasingly emphasised by the lay public. The Prince of Wales, Patron of the Royal College of Psychiatrists, at his address to the Annual Meeting in 1991, appropriately articulated this necessity:

"I do believe that we are in danger of cutting ourselves off into a world that recognises only mind and body. Training people for your profession and maintaining your professional skills are not simply about understanding and administering the latest drugs but about therapy in the original sense of healing - physical, mental and spiritual. If you lose that foundation as a profession, I believe there is a danger you will ultimately lose your way".

It can be argued that if mental health services in a multi-cultural society are to become more responsive to 'user' needs then eliciting the 'religious history' with any linked spiritual meanings should be a routine component of a psychiatric assessment, and of preparing a more culturally sensitive 'care plan'. 


\section{Transcultural facets}

\section{Issues of classification}

In the Diagnostic and Statistical Manual-IV for Mental Disorders (1994) it is recognised that a clinician who is unfamiliar with the "nuances of an individual's cultural frame of reference" may incorrectly regard as psychopathology those normal variations of behaviour, belief or experience which are particular to the individual's culture. The examples quoted are obvious and even simplistic, e.g. "a religious practice or belief, such as the hearing or seeing a deceased relative during bereavement (which) could be misdiagnosed as a manifestation of a psychotic disorder."

Nevertheless a useful new category is proposed: "Other conditions that may be a focus of clinical attention" a category which includes a sub-category 'Religious or Spiritual Problems' which has merged two distinct reasons for a medical consultation - the psychoreligious and psychospiritual. Psychoreligious problems are those restricted to the beliefs and practices of organised Churches or religious institutions, (e.g. Christian, Muslim, Hindu), such as loss of faith, intensification of religious practice and conversion to a new faith. Psychospiritual problems include a person's reported relationship with a Transcendent Being or Force which is not necessarily related to participation in an organised Church, or other religious organisation.

There is a need for more subtle multidimensional measures of religiosity in epidemiological studies to include, for example, a more detailed description of the ideological, emotional and sacramental aspects of Christianity. It is questionable whether the social descriptor 'religion' used in community surveys is useful at all, as frequently this category is misused to denote a Christian denomination, such as Methodist, rather than a specific religion. And without a detailed enquiry about the extent to which the religion is practised, such survey data are limited and could be misleading.

\section{Transcultural psychiatry}

An understanding of transcultural psychiatry is relevant here as religion is a "container of culture" and therefore has to be more fully understood. The rituals, beliefs and taboos of religion are profoundly important to the nature and structure of society and are vehicles whereby values, attitudes and beliefs are transmitted between generations.

Lewis (1976) in a definition of culture included religion as well as language as a specific vehicle of cultural transmission: "for our purposes, culture is simply a convenient term to describe the sum of learned knowledge and skills - including religion and languagethat distinguishes one community from another and which, subject to the vagaries of innovation and change, passes on in a recognizable form from generation to generation."

This definition emphasises the responsibility of a family for transmitting cultural variables between generations, and the importance of the parent/infant relationship. Any decrease therefore in the content and frequency of Christian education carried out by a Church or school, and less general knowledge about the tenets of Christian faith will diminish the transmission of religious values and beliefs between generations.

A transcultural perspective to an understanding of mental disorder provides a pragmatic way to consider the relationship of religious beliefs to psychiatric practice. However, central to this approach is a non-judgemental attitude; to be a 'participant observer' when describing the values and beliefs of others, especially when different to those of the observer, is essential. 'Cultural relativity' is an important additional socioanthropological principle in this context.

Desmond Pond (1973), Robert Lambourne (1963), Dennis Martin (1958), Frank Lake (1966), John Young (1993) were psychiatrists who understood from the inside the Christian religion and yet were able to retain objectivity in their writings, and so were aware of the "seamy side of religious belief" (Pruyser, 1991) when exploring the relationship of psychiatry to religion. Likewise Paul Tournier (1962), a Swiss doctor with psychotherapy training, was influential in recognising a specifically biblical holistic understanding of medical practice which emphasised the patient as a 'person' and the doctor's need to be sensitive to the spiritual aspects of medical work.

A greater understanding of the transcultural perspective to the practice of psychiatry will arise therefore from a greater sensitivity to the cultural and religious assumptions of health practitioners and patients. This approach also provides a bridge to understanding the relevance of religious beliefs to mental health service delivery.

Examples of the need for collaboration are provided by Yap (1965) who described how an understanding of religious beliefs was necessary for a full grasp of the psychopathology of depression in China. He explained how such understanding about the nature of depressive symptoms and the cause of manic-depressive illness was only possible if there was sensitivity to religious variables and drew attention to the meaningfulness of rituals and belief in the after life which determined the extent of grief and internalised anger. Religious prohibitions 
against suicide and homicide as well as the religious moulding of conscience were other central aspects of clinical depression which required an understanding of local values and beliefs. The nature of guilt was linked to a failure to appease parental figures or ancestors. In the West such guilt is more closely associated with the Christian emphasis on atonement for sins. To quote Yap "The individualistic, competitive and aggressively striving Protestant cultures may specifically produce unusual psychological distress, and the belief in original sin probably intensified depressive self reproach in a superficial pathoplastic manner".

\section{Priests, ministers and psychiatrists}

The nature and extent of collaboration between ministers, priests and psychiatrists is now considered within the context of their use of differing explanatory models (EMs) for mental disorder and the explanations for mental disorder used by parishioners as well as patients. Confrontation between psychiatrists and ministers of religion can occur when the minister's EM for mental disorder is restricted to a spiritual framework only with no awareness of biological or social causes. Similarly, when a psychiatrist has no understanding of the relevance of religious belief or spirituality to a mental health problem then confrontation is more likely.

Collaboration occurs when the EM of the priest includes an awareness of the complex nature of mental disorder, including biological factors, and when there is a familiarity with the range of treatments including medication and psychotherapy. A psychiatrist with a respect for the theological insights of a priest and a sympathy with the 'healing ministry' of a Church and aware of the ubiquity of spiritual beliefs is more likely to work closely with a minister of religion. Indeed, a psychiatrist who values a theological and sacramental reflection, and a priest who seeks professional help for himself, a colleague or relative will have much in common to discuss and evaluate.

Most psychiatrists readily recall depressed patients whose management was complicated because of an over-involved and uninformed minister or church member, or when a lack of faith due to the anhedonia of a depressive illness was regarded as a punishment for a misdemeanour reversed only by prayer and confession. In this instance religious belief had generated neurotic guilt. Pierre Solignac (1982) in his book The Christian Neurosis and Hans Kung (1987) Why I am stll a Christian point to anxiety generating authoritarian prohibitions within the Catholic Church. Gerrard Hughes (1985), on the other hand, was aware of how excessive
Protestant religiousness could provoke a mental health disorder. He quoted Frank Lake (1966) who described a 'Christian' disorder "hardening of the oughteries". Some charismatic worship is based excessively on the inculcation of true guilt for real sin and yet may also exacerbate neurotic (false) guilt. The former requires exoneration and forgiveness but such emphases exacerbate rather than relieve the guilt characteristic of a depressive illness.

Joint explorations between priest and psychiatrist could nevertheless include an evaluation of 'true' Christian experience and how it can be distinguished from an entirely neurotic form. Attempts to clarify the distinction between true and false guilt and the nature and causes of religious delusions are other areas of common enquiry.

Having religious counsellors as members of multidisciplinary teams is usually beneficial to patient care, although some psychiatrists find their presence difficult because of the unusual 'line management'. Ministers and hospital chaplains can be encouraged to maintain a sacramental pastoral ministry for mental health workers, although this role is difficult if the chaplain has become a counsellor or psychotherapist or has a diminished pastoral oversight for health professionals. Nevertheless such a ministry within the health service, whether hospital or community based, can help to reduce 'burnout'. A too rigid compartmentalisation between psychiatric practice and religious belief, especially when this is a separation between public and private, is often disadvantageous, and may discourage a recognition of the contribution of religious thought to psychiatric theory.

A transcultural perspective with an implicit cultural relativism together with a sympathy for interfaith dialogue provides a pragmatic platform for further exploration of these ideas. Lambourne (1963) anticipated a coming together of psychiatry and religion in an influential book entitled Community, Church and Healing.

He wrote:

"For the local church a careful assessment of the needs of the neighbourhood, and a plan for their amelioration which includes an imaginative correlation of secular administration, practical measures, prayer and witness and sacrament is no optional extra but is the very ground of the churches being".

A sectorised mental health service linked to the activity of Christian churches as well as other religious centres could indeed increase 'care in the community', and help restore an idealism and morality to a health service which has borrowed pseudo-religious language to underpin its secular reforms. 


\section{ORIGINAL PAPERS}

To the extent that the reforms have encouraged mental health services to be responsive to patients' needs and not driven a wedge between doctor and patient, they may enable an increased dialogue between ministers of religion and health professionals - as well as between parishioners and patients. Purchasers and providers of health care who neglect this facet of service delivery may be disadvantaged in the 'internal market' if they have encouraged a too secular service delivery. However, philanthropy, altruism and 'good practice' cannot be sustained by an incentive of financial gain, competition or 'Trust' enhancement alone. Some psychiatrists may wish theologians and philosophers to provide a spiritual and ethical reflection on what otherwise could become a solely secular task.

\section{References}

Hughes, G.W. (1985) God of Surprises. London: Darton. Longman \& Todd.

KUNG, H. (1987) Why I am stll a Christian. Edinburgh: T. \& T. Clark.

LAKE, F. (1966) Clinical Theology. London: Darton, Longman \& Todd.

Lambourne, R.A. (1963) Community, Church and Healing.

London: Darton, Longman \& Todd.
LEWIS, I.M. (1976) Social Anthropology in Perspective. London: Pelican Books.

LITTLEWOOD, R. (1992) DSM-IV and culture: is the classifcation internationally valid? Psychiatric Bullettn, 16, 257-261.

LUKOFF, D., Lu, F. \& TURNER, R. (1992) Towards a more culturally sensitive DSM-IV. Psychoreligious and psychospiritual problems. Journal of Nervous and Mental Disorders, 180, 673-682.

MARTIN, D.V. (1958) The Church as a Healing Community. Gulld Health, 26 Queen Anne Street. London.

POND, D.A. (1973) Counselling in Religion and Psychitatry. Ridell Memorial Lectures. Oxford University Press.

PRINCE OF WALES (1991) 150th Anniversary Lecture. British Journal of Psychtatry, 159, 763-767.

PRUYSER, P.W. (1991) The seamy side of religious belief. In Religion in Psychodynamic Perspective (eds. H.M. Malony \& B. Spilka). Oxford University Press.

SolignaC, P. (1982) The Christian Neurosis. London: SCM Press.

TOURNIER, P. (1962) A Doctor's Casebook in the Light of the Bible. London: SCM Press.

YAP, P.M. (1965) Phenomenology of affective disorders in Chinese and other cultures. In CIBA Sympostum Transcultural Psychiatry. London: Little Brown and Co.

YounG, J. (1993) Health, healing and communication. In The Gospel and Contemporary Culture led Montefiore H.J. Cossells.

John L. Cox, Professor, Department of Psychiatry, School of Postgraduate Medicine, Keele University, Staffordshire ST4 7QB 